\title{
Playing in the Woods: Youth, Leisure and the Performance of Gender Relations in Rural Newfoundland
}

Dr. Moss E. Norman, Post-Doctoral Fellow, Community-University Research for Recovery Alliance, Memorial University

Dr. Nicole Gerarda Power, Assistant Professor, Department of Sociology, Memorial University

Dr. Kathryne Dupré, Associate Professor, Faculty of Business Administration, Memorial University

\footnotetext{
Abstract

Based on qualitative interviews and focus groups with youth (12-24 years) living in rural, coastal Newfoundland, Canada, we examine how leisure practices within this context served to reproduce and naturalise localised gender relations. More specifically, we argue that the participants drew upon dominant discursive constructions of rural leisure to reiteratively enact a binary distinction between the 'town' as a space of constraint, youthadult tensions, and consumerism in contrast to the freedom and privacy of the 'woods'. This dichotomy was mapped onto gender binaries, where the town was coded as feminine and the woods masculine. We argue that these constructions served to mark the boundaries of normative gender leisure practices in the production of embodied gender subjectivities.
} 


\section{Introduction}

"Her crew consisted of two fourteen-year-olds who, I decided, must have been among the luckiest boys alive, spending their summer moseying in and out of little harbours from Port aux Basques ${ }^{i}$ to St. Pierre under the amiable eye of their uncle, Skipper Hubert Spencer” (Bay of Spirits: A Love Story, Farley Mowat ${ }^{\mathrm{ii}}$, 2006: 98-99).

In the above quote Farley Mowat paints an idyllic picture of growing up in rural Newfoundland, Canada in the 1960s. The difficulty is, however, that, like most of his writings on Newfoundland, Mowat only recounts a partial story as seen from his adult, masculine vantage point. In suggesting that the boys’ are the "luckiest alive" he draws upon the well-established trope of the 'rural idyll' (Jones, 2007; Philo, 1992; Valentine, 1997), inferring that a rural childhood spent outdoors is somehow more innocent, pure and inherently pleasurable than growing up in the city. In so doing, he erases the multiple experiences of rural childhood. For example, the absence of girls and women in the image he paints bespeaks prevailing patriarchal relations that have been identified in rural, Atlantic Canadian contexts (see Marshall, 2001; Power, 2005), while the benevolence of the uncle's "amiable eye” occludes the very real power imbalances that characterise child-adult relations (Sibley, 1995). In other words, not all rural youth have equal access to the 'rural idyll' that Mowat cherishes. Indeed, the 'rural' itself is dominantly coded as a masculine space (Cloke, 2005), a coding that gives rise to localized gender performances and relations. In this paper we problematise the deep and 
cherished cultural constructions of the 'rural idyll', as well as the seemingly 'natural' place of boys in it (Cloke, 2005).

Using qualitative data collected from focus groups and interviews, we explore how discursive constructions of 'the rural' are taken up in the everyday leisure practices of rural youth (12-24 years) living on the southwest coast of Newfoundland, Canada. By submitting the narratives of the participants to a poststructural discourse analysis (Wright, 2004), we demonstrate how gender relations are naturalised within place-based discourses and discursive practices in the construction of particular embodied subjectivities. We unpack how the discursive construction of the 'rural idyll' is taken up and embodied in the materialisation of masculine subjectivities within the specific context of rural, coastal Newfoundland. In the following section we overview relevant theoretical literature pertaining to the discursive construction of 'the rural'.

\section{The Discursive Constructions of 'the Rural'}

Global mythical constructions of out of the way places are largely "imagined geographies” (Cloke, 2005) or discursive constructions, where remote locations come to be culturally coded in particular ways. One dominant coding, scholars have noted, is that of the 'rural idyll' (Valentine, 1997). According to the ethos of the 'rural idyll', remote places are understood as safe, free, close to nature, peaceful, innocent and healthy communities where "everybody knows everybody" (see Leyshon, 2008; Little and Leyshon, 2003; Matthews, Taylor, Sherwood, Tucker and Limb, 2000; Ni Laoire, 2007; Rye, 2006). Indeed, such qualities overlap with and inform constructions of the 'rural childhood idyll' (Jones, 1997, 2000, 2007), where it is assumed that the countryside is the 
'natural' place of childhood (Valentine, 1997). These constructions of the rural gain intelligibility when contrasted with the 'urban' that is dominantly represented as dangerous, crowded, polluted, impure (Leyshon, 2008) and child hostile (Jones, 2007). On the flip side, however, the 'rural dull' (Rye, 2006) is also a central representational metaphor. Here, rurality is constructed as consisting of regressive, premodern and backward communities (Jarosz and Lawson, 2002; Li Naoire, 2008) that offer youth ‘nothing to do’ and ‘nowhere to go’ (Kenway, Kraack and Hickey-Moody, 2006). Similarly, constructions of the rural as 'empty' and 'dying' (if not 'dead') are contrasted with the urban as 'full,' 'alive,' active and vibrant. These multiple and contradictory constructions of the rural are not inert, but provide cultural resources for understanding, experiencing and consuming rurality (Narin and Panelli, 2009) and are taken up and deployed in the formation of rural identities (Leyshon, 2008). In this way, "place-based narratives [are]...imbued with social power, and have implications for...young peoples' sense of self, their thoughts about the future, and the constitution of youth cultures” (Vanderbeck and Dunkley, 2003: 256). In other words, the identities of rural youth are embedded within and constituted through discursive constructions of place.

The recognition of the multiple, fluid and relational constructions of rurality indeed correspond with and are constitutive of multiple and fluid experiences of 'the rural'. For instance, Cloke (2005) argues that uniform constructions of the 'rural idyll' render invisible the power relations that produce those "othered countyside” (Philo, 1992) experiences that exist at the cross roads of social class, gender, age and sexuality. Rural scholars have noted how experiences of 'the rural' are mediated by constructions of age (i.e. Jones, 1997, 2000; 2007; Valentine 1997; 2008), gender (i.e. Dunkely, 2004; Kraack 
and Kenway, 2002, Kenway et al., 2006, Kenway and Kraack, 2009; Leyshon, 2008;

Tucker and Matthews, 2001), social class (i.e. Alston and Kent, 2009; McGrath, 2001;

Rye, 2006), sexuality (Bell, 2000) and race (Hogan and Pursell, 2008). These authors

illustrate how the entanglement of ruralities, rural experiences and rural identities is thus far too complex and enmeshed to be adequately represented under the umbrella trope of the 'rural idyll.' To this end, Epp and Whitson (2001: xxviii) suggest that "more than ever...the metaphor of 'tight-knit' misses the frays, tears and stresses in the fabric of rural communities". In the following section we examine some of the "frays, tears and stresses" that characterise the recreational experiences of young people living in remote places.

\section{Youth, Rurality and Recreation}

While idyllised constructions of one uniform 'rural childhood' have given way, under critical scrutiny, to the recognition of the multiple possibilities and experiences of 'the rural' (Smith et al., 2002), the myth of the rural as the 'natural' place of childhood nonetheless remains dominant in cultural imaginings (Jones, 2000, 2007). In contrast, the adolescent or teen presence is constructed as 'anti-idyll' as their presence is thought to “introduce disquiet, crime and immorality” (Matthews, Limb and Taylor, 1999) into what appear to be otherwise harmonious and peaceful settings. Indeed, teenagers are "outsiders within” their own communities (Kraack and Kenway, 2006; Narin and Panelli, 2009), as they do not quite belong to the category 'childhood' nor 'adulthood'. The liminal status of teens as not entirely belonging within their communities, and not entirely being one age category or the other, represents a threat to both the adult/child binary and the rural idyll, a threat that manifests in adult/youth spatial struggles. 
Given the tightly-knit social fabric of rural cultures, where 'everybody knows everybody', along with the shortage of youth designated spaces (Marshall, 2001; Panelli, Narin and McCormack, 2002), teens are particularly susceptible to adult surveillance and control (Leyshon, 2008; Valentine, Holloway, Knell and Jayne, 2008). For instance, in their study of teenagers living in rural Vermont, Dunkley (2004) found that young people struggled to use public spaces and private retail outlets, and complained that they were constantly being 'moved along' by adults. Our current research has revealed similar spatial struggles, where the participants complained of being "stereotyped" and "discriminated" against by adult populations in the streets, parks and shopping spaces of rural Newfoundland (Norman, Power and Dupre, 2010). For their part, however, teens are not passive in these spatial struggles, but rather engage in a "continuous politics of negotiation through the use of creative but transient strategies...to challenge the constructions and control of older people” (Panelli et al., 2002: 113). Indeed, rural spatial struggles are not experienced uniformly by young people, but rather are shaped by gendered expectations and embodied spatial performances.

Scholars have found that girls living in rural contexts are accorded less spatial mobility than boys and are bounded closer to home (Dunkley, 2004; Matthews et al., 2000). The car seems to be central to the increased spatial mobilities of young men (Dunkley and Paneill, 2007). Somewhat at odds with these findings, Kenway and Kraack (2002) and Narin and Panelli (2009) found that boys complained of being particularly 'out of place' within their rural communities and thus hyper-vulnerable to adultist surveillances and disciplinary controls. Other scholars, however, have suggested that rural locales offer more recreational opportunities for boys and young men than they do 
for girls and young women (Bye, 2009; Kenway et al., 2006; Ward, 1990). While girls can adopt "quasi-male" or tomboy identities within rural contexts (Jones, 1999), teenage girls and young women are thought to be out of place and at odds with the recreational spaces and practices of rurality. Of these gendered, rural topographies, Kenway et al. (2006) write that non-city locations are often constructed as:

dead zones for girls because there is 'not enough shopping' and because they associate outdoor lifestyles with masculinity. [As a result] [g]irls are generally constructed as antithetical and are represented as inactive and passive in relation to [rural lifestyles]. (99)

Spatial constructions of the 'rural' and the 'urban' are multiple, fluid and, at times, contradictory. Constructions of the rural as a tough, free, independent space (Hogan and Pursell, 2008), on the one hand, and as a backward and uncivilized space (Jarosz and Lawson, 2002), on the other, sits in binary opposition to contradictory constructions of the urban as civilized, sophisticated, as well as congested, unsafe, and dirty (Jarosz and Lawson, 2002; Jones, 2007; Vanderbeck and Dunkely, 2003). These multiple and shifting constructions of the rural and urban, although messy, nonetheless serve as central representations in the performance of rural masculinities and, indeed, are reflective of the fragmented and shifting masculine subjectivities (Pringle and Markula, 2005) that young men performatively embody.

\section{Rural Masculinity}

Just as there is no one 'rural', neither is there a uniform 'rural masculinity' (Campbell and Bell, 2000; Cloke, 2005; Little and Leyshon, 2003). In an attempt to avoid the pitfalls of constructing a singular or essentialist 'rural masculinity', Campbell and 
Bell (2000) articulate the distinction between, on the one hand, the "masculine in the rural" and, on the other, the "rural in the masculine". With the "masculine in the rural" they refer to the "various ways in which masculinity is constructed within...rural sites and spaces” (540). In the "rural in the masculine," they aim to highlight the range of representations that interlock with and are constitutive of understandings of masculinity. Thus, discourses of rurality and masculinity have a mutually constitutive relationship, whereby each gains its intelligibility in and through its representational proximity to the other. Thus, cultural representations of masculinity draw upon rural outdoor recreational adventures and conquests, such as hunting, fishing and snowmobiling (see Bye, 2003, 2009), as well as rural labour practices, such as farming, mining, and fish harvesting (see Kenway et al., 2006; Little, 2002; Power, 2005), in articulating what it is to be masculine. Nowhere is this mutuality more evident than in the Marlboro Man, where the meanings associated with the rural, free ranch cowboy are drawn upon in the commodification of Marlboro brand cigarettes, such that even city-dwelling men are able to identify with the image of masculinity conjured in such advertising (Peter and Bell, 2004). However, individuals also live in rural contexts and representations of the "rural in the masculine" serve as central discursive resources whereby boys and men, as well as girls and women, come to understand and experience their localities and their gender identities within these localities. Indeed, for rural youth, recreational and leisure practices serve as central performances through which boys and men embody gendered subjectivities (Kraack and Kenway, 2002). These recreational activities reflect dominant cultural representations of the rural in the masculine, or discursive constructions that link rural masculinity to, for example, the freedom and independence associated with the outdoors (Bonnett, 1996; 
Kenway et al., 2009), conquest and control of nature (Brandth, 1995; Bye, 2009; Liepins, 2000), survival in harsh, rugged climates (Hogan and Pursell, 2008). Such representations are not necessarily accurate accounts of how masculinity is performed in rural contexts, but nevertheless serve as important resources that individuals can draw upon in understanding and experiencing their rural contexts. They provide boys and young men, for example, with culturally available categories for understanding, experiencing and performing appropriate versions of masculinity within rural localities (Campbell and Bell, 2000; Cloke, 2005). Representations of rural masculinity, therefore, are not innocuous and benign, but rather are animated through, and constitutive of, gendered relations of power and embodied hierarchies of privilege and oppression.

Given the link between masculinity and representations of masculinity in the rural, Little and Leyshon (2003) suggest that the task is to interrogate how particular forms of the body and bodily practice gain power within specific rural contexts by taking up and embodying constructions of 'the rural'. Dominant constructions of 'Nature' code it as feminine (e.g. Mother Earth) (Jones, 1999), a construction that has given rise to the masculine imperative to penetrate, conquer and control the wild, untamed and leaky 'essence' of the natural, feminine-Other (see Brandth, 1995; Little, 2002). Indeed, central to the outdoor performances of rural masculinity is the acquisition of the necessary technological skills to control and manipulate the natural environment, whether it is driving tractors in the cultivation of farmland (Brandth, 1995; Liepins, 2000) or using guns and snowmobiles in hunting expeditions (Bye, 2003, 2009). From spatial recreational practices, boys and men gain a "topographical intimacy" or a deeply embedded corporeal connection with the spaces and places of rurality (Lippard cited in 
Kenway et al., 2006). Indeed, within rural contexts the outdoors is coded as masculine spaces of play and work, while the indoors is coded as feminine (Dunkley, 2004; Kenway and Hickey-Moody, 2009). Thus, outdoor discursive practices of conquest and control have been identified as central to the embodiment of rural masculine subjectivities, a notion that Bull (2009) takes issue with. In his research into the angling cultures of men in the UK, he suggests that parallel to masculine practices and performances of the aggressive control of nature, there are those that "respond to nature, nurturing, shepherding and cultivating, rather than domineering and subjecting” (emphasis in original: 456). Indeed, Bull serves to remind us that there are multiple ways of doing masculinity and being masculine in rural contexts and that "not all men thrive in rural spaces” (Cloke, 2005: 52). To this end, in the Atlantic Canadian context, Marshall (2001) found that motorised recreational vehicles were increasingly being used by girls and women, thus allowing them to experience some of the same "topographical intimacies" traditionally experienced by boys and men. Similarly, in rural Norway, Bye (2009) found that recreational vehicles were increasingly being used for family outings, albeit, with men continuing to control (and perhaps guard) technology and spatial knowledge, thus preserving their masculine ascendancy. From this review of the literature, it is evident that constructions of the rural and their relationship to performances of masculinity are complex and contextual, and thus warrant further investigation. 


\section{Methods}

\section{Context}

The data presented in this paper draw from the qualitative component of a mixed methods project ${ }^{\mathrm{iii}}$ that explored the quality of work and recreation experiences of youth living in the rural, coastal regions of southwest Newfoundland.

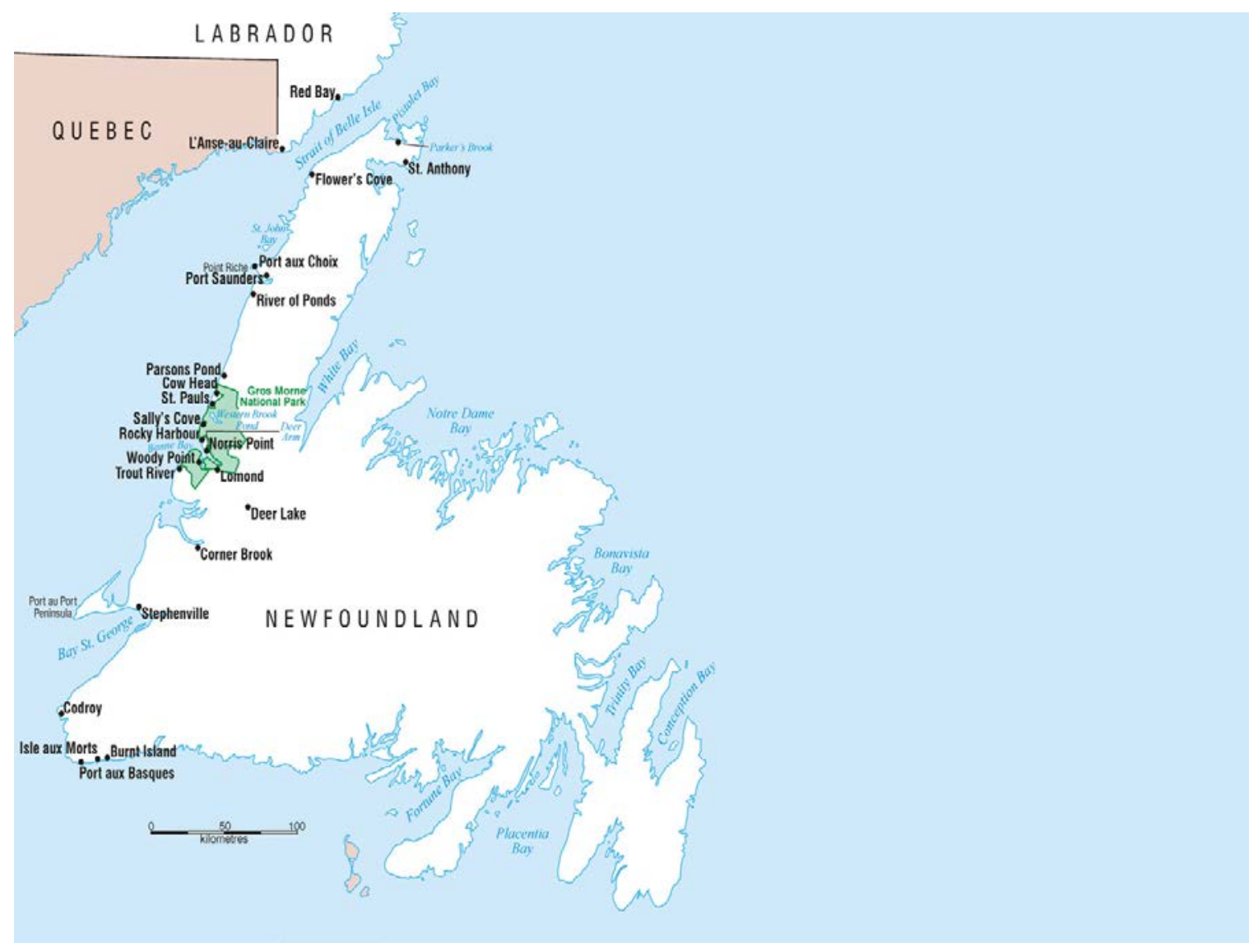

Figure 1

This project is part of a larger program of research, the Community-University Research for Recovery Alliance (CURRA) $)^{\text {iv }}$. The CURRA is a five-year "research program of innovative, interdisciplinary research projects related to helping communities and 
organisations along Newfoundland's west coast develop strategies for the recovery of fish stocks and fishery communities" (www.curra.ca). Like rural coastal communities elsewhere, fishery communities on Newfoundland's west coast are negotiating the effects of environmental, industrial and regulatory changes. Fish stock collapses and associated fish plant closures, and the reorganisation of the harvesting sector have severely limited employment options for youth in the fishery. Employment in the research area is concentrated in the resource extraction, construction and service/tourist industries, all of which are highly seasonal. Like the province more generally, the research area has also experienced population declines in the last 15 years as a result of outmigration.

With the collapse of fish stocks and fish-related industries, jobs have become increasingly sparse and this has had cascading effects on all aspect of these communities (Ormer, 2007). Although many of the research participants spoke favorably of their communities, they nonetheless frequently described their communities as "in decline", recounting the friends, family, and businesses (particularly consumer retail outlets) that had departed in recent years (Norman et al., 2010). As such, many of the youth talked about their communities as having "nothing to do", "nowhere to go" and "nobody to hang out with”. Indeed, it was common for the participants to describe their towns as adult centric, offering few recreational and leisure opportunities for young people. One source of recreation, however, was the "woods" or expansive natural landscape that surrounded these communities. Unlike many other rural settings, where the 'natural' spaces bordering the town are not 'free' and openly accessible, but privately owned (Philo, 1992), much of rural Newfoundland is government owned crown land. As such, rural residents are able to use the landscape for various recreational and leisure activities, such 
as snowmobiling, four-wheeling, hiking, hunting, camping and so on. Although many of the communities were situated near or in protected lands, including provincial, national and internationally recognised parks ${ }^{\mathrm{v}}$, many of the participants talked about enjoying the "freedom" to use the "woods" at their own discretion. That said, the participants shared stories of restrictions imposed on their "free" roaming of these wooded spaces, particularly with respect to four-wheeled, all terrain vehicles, where adult community members and the police alike attempted to govern their recreational "freedom" (i.e. speeding, not wearing helmets, being too young, driving on the road and driving in environmentally sensitive areas).

Geographically, the island of Newfoundland is euphemistically—and somewhat appropriately so-referred to as "the rock". The landscape of coastal western Newfoundland is diverse, varying from rolling rocky terrain, to rocky mountain ranges, to vast grassy-moss barrens, to miles of sandy beach coastlines. Indeed, it would be difficult to capture the diversity of the landscape of western Newfoundland in a brief summary. Nonetheless, "the woods," as the participants referred to them, are characterized by low, relatively sparse growth of ash, elm, birch and white pine. Throughout much of the wooded or uncultivated spaces of Newfoundland there are extensive trail systems, few of which are regulated or maintained in any sort of formal way. Many of these trails serve as access points to recreational "cabins" with, as many of participants explained, going to the cabin being an important source of recreation.

\section{Data Collection}

Norman (the lead author) spent a total of four months between April 2009 and June 2010 living in various communities on the west coast of Newfoundland where he 
conducted qualitative focus groups and interviews. Research was conducted in a total of eight communities, including Burgeo, Burnt Islands, Isle aux Morts, Port aux Basques, Codroy, Stephenville, Woody Point and Trout River (see Figure 1). Participants were recruited through regional sectors of the Community Youth Network (CYN), a provincially funded initiative designed to support education and recreation opportunities for youth, and the Western District School Board of Newfoundland and Labrador ${ }^{\text {vi }}$. Interviews and focus groups were conducted in quiet, semi-private locations, usually in a classroom or boardroom at local schools or CYN facilities. Focus groups and interviews were informed by relevant literature and a pilot project ${ }^{\mathrm{vii}}$. Questions included "What do you do for fun around here?”. "Do boys and girls do different things for fun?” as well as more general prompts, such as "Tell me about the sorts of things you would do on a typical Saturday or day away from school”. Given our conceptualisation of youth as “active agents in their own decision making and identity formation” (Leyshon, 2008: 4), research discussions were treated as "inter-subjective conversations" (Kvale, 1996) where, to the degree possible, questions were evolving and emerging from specific intersubjective contexts. Focus groups and interviews, however, were generally organised around themes of work, physical activity, recreation and leisure experiences. When considering focus groups and interviews, ninety-eight youth between the ages of 12-24 years participated in the research. The focus groups were conducted in three age groups, $12-15(\mathrm{~N}=28)$ years, $16-18(\mathrm{~N}=30)$ years and 19-24 $(\mathrm{N}=26)$ years, with six focus groups in each age category. Focus groups lasted between thirty-five minutes and 2.5 hours, depending on the age of the participants and how much time was available. Additionally, fourteen one-on-one interviews were conducted with rural youth. Interviews ranged from 
thirty-five minutes to one hour and forty minutes. Focus groups and interviews were digitally recorded and transcribed verbatim. Pseudonyms have been used to protect the participants, however, names of towns and villages have not been altered. All transcripts were analysed using NVivo and were submitted to poststructural discourse analysis (see Edley, 2001; Wetherell, 2003; Wright, 2004).

\section{Qualitative Research Tradition}

Within poststructural epistemology, the relationship between power, language and subjectivity is a critical site for investigation (Weedon, 1997; Wright, 2004). Language is not assumed to be a neutral medium of communication. Rather, what is sayable within a particular historical context is governed by discourse. Discourse refers to a set of patterned and recurring frameworks of meaning that shape and bring into existence the very entities that it identifies, describes and names (Foucault, 1972). For

poststructuralists, discourse is central to the cultural production or, as Butler (1993) would refer to it, the materialization of gender subjectivities. Thus, discourses of masculinity—and femininity for that matter—-operate as relatively cohesive systems of thought that identify particular bodies as male [and others as female] and particular human performances as masculine [and feminine]” (Pringle and Markula, 2005: 477). Discourses of gender, according to Butler (1993), are performative in that they constitute as an effect the very subjects that they appear to express. In other words, the subject does not preexist gender discourse, but rather the subject is materialized as a gendered subject in and through their enactment or performance of culturally available gender discourses. Representations of the "rural in the masculine", for example, serve as discursive resources within which youth living in rural settings can take up and perform particular 
ways of being masculine. Thus, discourses of masculinity forcibly materialise certain ways of performing gender, while foreclosing others. An individual's gender subjectivity, therefore, is not static and fixed, but rather performative in that it gains the appearance of essence though the reiterative enactment of gender discourses over time. Importantly, not all individuals are equally positioned in relation to discourse, with certain discourses being culturally available to some while foreclosed to others, thus giving rise to more or less powerful ways of being (Weedon, 1997). For instance, discourses of rural masculinity interpellate some bodies to take up and occupy masculine subject positions within rural spaces—such as engaging in outdoor recreational practices like fishing, hunting and snowmobiling — thus giving rise to culturally privileged and powerful ways of being, while simultaneously making it difficult for other bodies to occupy such positions (see Kenway et al., 2006).

The task of the poststructural discourse analyst, therefore, is threefold: to identify the discursive subject positions available within a particular narrative or transcript; to discern how individuals discursively enact or perform such positions; and to determine the consequences such discursive performances represent to the broader socio-historical context (Wetherell, 2003; Wright, 2004). In the sections that follow, we aim to analyse the narratives of the participants to discern how they take up and enact subject positions within discourses of gender in the production of a contextually specific set of gender relations and how these gender relations serve to materialise particular embodied subjectivities. 


\section{Findings}

\section{Overview}

The participants understood and talked about their rural leisure experiences through a number of discursively constructed binaries which, as we will argue, were central to rural gender relations and the construction of gender subjectivities. In this paper, we take up and interrogate how the participants constructed a town/woods binary and how this binary was formative to gender relations within this specific place-based context. We have divided the findings into three sections. In the first section, we explore how the participants constructed and experienced the binary division between 'the town' and 'the woods'. In the second section we interrogate how the binary opposition between the town and the woods maps onto gender binaries, thus rendering intelligible particular localised gender relations. The third and final section unpacks how 'the town' was discursively constructed as feminine and the implications this has for gendered subjectivities.

\section{Rural Adolescence and the Town/Woods Binary}

Many of the older, teenage participants articulated a distinction between townlife and 'the woods' in narrating their rural leisure experiences. Whereas nature or the woods were described as places of freedom, independence and privacy, the participants contrasted this to the rule-bound, adultist cultures of their towns. In particular, many of the teenage youth described their town-based leisure practices as being marred in a constant spatial struggle with mistrustful adults who were chronically suspicious of teenage youth, stereotyping them as destructive, disrespectful and perpetually up to no good. Such stereotypes conspired against young people, particularly teenagers, making 
them feel as though they did not belong in the public and private spaces of their rural towns, including retail stores, which the participants identified as central to their recreational practices (Norman et al., 2010). Many of the participants described being "bored” and having "nothing to do" and "nowhere to go” within their rural, Newfoundland towns. Although often these sentiments of 'boredom' were contrasted with what they imagined to be the abundant leisure opportunities of more urban locations, they were also in reference to the adultist, rule-bound, striated spaces of their rural communities. The spatial configurations of Deleuze and Guattari (1987) have been usefully deployed to characterise the spatial experiences of young people living in rural settings (see Jones, 2000). Deleuze and Guattari distinguish between striated and smooth spaces, not as absolutes, but as overlapping and contested spatial metaphors, where striated refers to the rational imperative to tame and control space through reducing it to regulatory laws, maps and organization, whereas smooth space is characterised by intensities, freedom of action and impermanence. For the youth, the adultist gaze of rural town life acted as so many striations that made it near impossible to go anywhere or do anything without being interrogated, persecuted and harassed by adult-Others.

Moss: What could be added to your community to make it better?

Trevor: $\quad$ Like having somewhere to go or something to do. If I can go out and find someone to hang out with, we usually end up sittin’ down around somewhere or something like that. Even that's gettin’ a little bit harder to do now because a lot of the places you want to go to sit down, you can be there for like five seconds and somebody will call and be like "Get off our 
property or we're calling the cops!” There's places like that, that if you go you're gonna get yelled at. [19 year old male]

Moss: Why?

Trevor: $\quad$ People have this weird conception of teenagers now, I guess they always did, but I guess now it’s more so magnified, I guess you could call it, that we're all a bunch of troublemakers.

Although not all youth spoke about adult-youth relations in terms of a spatial struggle, it was nonetheless common for the participants to talk about adults as having "stereotypes" against teenage youth, whether warranted or not.

Moss: What do you think of adults in this town?

Martin: Well, I find that they're stereotypical most of the time. If like they stereotype people like teenagers, against people who wear hoodies ${ }^{\text {viii }}$, like if you wear a hoody they figure you go around smokin’ dope all the time. I find that they're really stereotypical and that they're really cautious over what they do when they're around them [youth].

In line with the findings of others (see Dunkley and Panelli, 2007; Kenway and HickeyMoody, 2009; Kraack and Kenway, 2002; Narin and Panelli, 2009), many of the participants talked about feeling persecuted within their communities. The participants talked about the rural communities as being particularly constraining to young men, thus further entrenching feminine constructions of the town. Similar to the findings of other 
scholars in different rural contexts (Kraack and Kenway, 2002; Narin and Panelli, 2009), several of the participants explained that boys and young men were especially vulnerable to adult suspicion, harassment and surveillance, and were disproportionately targeted by adults as "troublemakers" in need of discipline and control. Although teenage females shared similar stories of adult-youth power imbalances, there seemed to be a tacit acceptance that teenage boys faced particularly harsh treatment within the rural communities under investigation. This, however, is not to suggest that rural Newfoundland communities are more conducive to the leisure activities of girls and women, but rather that the participants spoke about their communities as such. Indeed, other scholars have found that rural settings are particularly constraining spaces for girls and women with relatively few recreational and work opportunities as well as especially rigorous social censorships (e.g. Dunkley, 2004; Matthews et al., 2000). Such gendered spatial experiences have been found to contribute to the relatively higher rates of outmigration amongst young women in the Atlantic Canadian context (Corbett, 2007). Thus, it is not that the rural towns are more feminine, but rather that they are constructed as such when contrasted with the relative freedom of the woods. In other words, descriptions of adult surveillance and persecution contrasted sharply with the freedom, independence and adventure associated with the woods.

In contrast to the adultist, striated spaces of the town, many of the participants spoke about the woods as a sort of smooth space shorn of rules, regulations and adult control. Indeed, the participants described the woods as offering a buffer or shelter from the power-hierarchies of town-life where they could "roam" freely, "get away from everybody else" and, as one participant explained, have "fun [...] without nobody 
need[ing] to know what we're doin' in there”. Rural Newfoundland, with its abundance of land- and seascapes, thus proved to be an ideal location for young people to secure a reprieve from the discrimination and harassment that many of the youth felt they were subjected too within their rural towns. Many of the teenage participants described the woods or country as a smooth or “differently striated space” (Jones, 2000) where they could be independent, use their imaginations and get away from the prying eyes of others, particularly adults.

Moss: What sort of things do you do for fun?

Blake: $\quad$ Right now we're buildin' a camp in ah old road for something to do. We goes in on our quads ${ }^{\mathrm{ix}}$, right. [14 years old]

$[\ldots]$

Moss: $\quad$ And this camp that you're building [back in the woods], ah is it just your camp or your family’s camp?

Blake: $\quad$ No, it's just a bunch of [male] teenagers going in on it for something to $\mathrm{do}^{\mathrm{x}}$.

Moss: $\quad$ How many teenagers?

Blake: $\quad$ Seven of us.

$[\ldots]$

Moss: $\quad$ Ah neat, and what are you going to do with the camp?

Blake: Just somewhere to go to get away from everybody else. Like somewhere to go. We go troutin' [fishing] in the spring and summer and we go there ski-dooin' in the fall and winter. 

Moss: $\quad$ And what do you mean "get away from everybody else”?
Blake: Well, like at a sleep over at our house like you get up the next morning and that there's nothing to do. But we go out there and have a sleep over, we get up the next morning we could cook our breakfast. Like you feel more independent.
Jason: $\quad$ Feel like you're back in the old days livin' out in the woods and that. [12 years]
Moss: $\quad$ And you like that?
Blake: $\quad$ Yeah, I lives ${ }^{\mathrm{xi}}$ for that stuff.

The freedom associated with "getting away" from the adultist centred worlds of rural communities was indeed enhanced (although not necessarily dependent upon) the aid of recreational vehicles such as snow mobiles, dirt bikes and all-terrain vehicles (also known as “four wheelers” or “quads”):

Moss: $\quad$ Say quading, snowmobiling — does anybody do that [around here]?

Fraser: $\quad$ Oh yeah! [18 years]

Kiva: $\quad$ That's big out our way. Especially since you can go from anywhere in a ski doo to anywhere you want. [18 years]

Fraser: $\quad$ Yeah, and it's not like you have set ways, you kinda roam. [18 years] $[\ldots]$

Brian: As long as you have like insurance or whatever on your ski-doo, you're fine. [18 years] 
Kiva: $\quad$ You can go anywhere. [18 years]

Brian: $\quad$ It's not legal, but we do. [18 years]

Fraser: $\quad$ Yeah, it’s just a little bit of freedom for us in a small town. [18 years]

Motorised vehicles empowered youth, particularly teenage youth, to expand their territorial roaming, thus allowing them to move into more remote locations, away from the constraints of town-life, but also gave them the ability to transform the striated, rulebound spaces of the town, into the smooth roaming, "go anywhere you want" spaces of the country or woods. The expansive wooded and barren spaces that surround rural Newfoundland communities were repeatedly referred to as offering children and youth 'freedom', 'independence', privacy and the ability to explore. Thus, in describing the role that the woods played in their leisure experiences, many of the participants took up discursive constructions of the 'natural' as wild, uncultivated, pre-modern smooth spaces (MacNaughton and Urry, 2000). As scholars have noted, however, (im)mobility is inevitably linked to relations of power (Massey, 1998). Some bodies have disproportionate access to the recreational use of the 'natural' spaces of rural Newfoundland, while others encounter obstacles to the access of such leisure practices.

\section{Masculinising 'the woods'}

Discourses of gender powerfully shaped how the participants understood, experienced and practiced leisure within rural contexts. Indeed, scholars have noted that the outdoor leisure practices of rurality are culturally coded as masculine (Kenway and Hickey-Moody, 2009). For example, Cloke (2005) writes that the woods are constructed as "places for masculinised adventure which conflate a cultural mastery of nature with 
practices of exploration and adventure in which boys and men can perform brave feats in which they confirm and reconfirm their masculinity” (Cloke, 2005: 52). Such discursive representations produce what Cloke refers to as "imagined geographies” which serve to highlight some rural recreational experiences, while erasing or, at the very least, rendering less visible those "non-hegemonic aspects of rural gender relations” (53). In this section, we examine how discourses of gender and rurality enabled some stories and experiences of rural leisure-pleasures while constraining others. More specifically, we suggest that the town/woods binary was unintelligible outside of other, more culturally dominant binaries, including the dichotomy between masculinity/femininity. The reiterative citation of the binary between town/woods in the stories of the participants gave rise to gendered spatial relations and particular embodied rural subjectivities.

Teenage girls and women, many of the participants suggested, were not interested in outdoor recreations such as hunting and fishing nor, they suggested, were they interested in dirt biking, quading or snow mobiling. These recreational practices were understood as something that boys and young men did. For many of the youth, such gender constructions went unquestioned and seemed to be the 'natural' order of things. We argue, however, that such gendered recreational practices were largely constituted through the citation of broader discourses that construct the rural outdoors as masculine spaces of play (Cloke, 2005), constructions that made it difficult (although not impossible) for rural teenage women to recreate in the same ways as teenage men. As such, young teenage women were less likely to talk about hunting, fishing, quading and four-wheeling as integral aspects of their leisure practices. When they did talk about doing these activities, they often did so in relation to the "boys," often sharing stories 
about riding on the back of snow mobiles or quads with their fathers, brothers and boyfriends on their way to the cabin, to go camping or to a bon fire in the back country. Thus, recreational experiences of the outdoors or the woods were gendered, where teenage boys generally seemed to inhabit larger geographic territories, while teenage girls seemed to experience obstacles and constraints to the sort of spatial freedoms that the boys enjoyed. Importantly, the gendered occupation of space appeared to be mediated through different (gendered) relationships to motorised, off-road vehicles.

Moss: Do you think boys and girls do the same activities?

Mark: $\quad$ Um, for the most part, yeah, but there are a few things that boys will do that girls won't and the main thing is ski doing and ATVing [driving an off-road recreational vehicle], but there are a few girls that will do that. And hunting is another thing that most girls won't do that guys will. But for the most part they do similar stuff. [15 years]

Moss: Do you think girls and boys do different things in this town? Martin: $\quad[\ldots]$ girls and guys do the same things, they go to the dances, they hang around, girls just take a longer time to get ready [pause] and I don't know a lot of girls that could ski doo and use dirt bikes, but yeah, they somewhat do the same thing.

Although it was often difficult for the participants to identify differences in the recreational practices of boys and girls, the use of motorised, off-road vehicles was 
routinely coded as a masculine practice and something that only a "few girls" did. The participants disproportionately invested in this particular difference as illustrative of the supposedly large gender differences in the recreational practices of boys and girls. While there were some teenage girls that used snowmobiles and dirt bikes, for example, they were understood as exceptions to the seemingly 'natural' order of the local leisure scene. Moreover, most of the young women who indicated that they did use motorised recreational vehicles suggested that they used them closer to home and usually just to get “around town”. Indeed, discursive constructions of gender difference were salient to the participants' understandings and explanations as to why girls and boys engaged in different rural recreational practices.

The boys in particular suggested that the girls were adverse to getting dirty and were more interested in “shopping”, make up and engaged in "safer” and less exciting recreational practices that centred around town-based activities. Indeed, these gender differences were seemingly naturalised in and through discursive constructions of the woods as masculine and the town as more feminine.

Moss: $\quad$ Why do you think those differences [are]?

Mark: $\quad$ Um, with hunting and ski doing, I think it's more of like, it's more of an excitement, like an adrenalin rush kinda thing, but generally girls don’t want to have that kinda thing because they prefer to be a bit more safer, like they do safer stuff generally compared to what guys do and I don’t really know why it's like that, it's just one of those things that are. 
Devon: $\quad$ No offense to girls but they're kinda, a few of them are girlie girls. [14 years]

Moss: What do you mean by "girlie girls”?

Devon: $\quad$ Like they're afraid of breaking their nails. And they like flip out if they're not wearing any make up or such and such.

Moss: $\quad$ So it wouldn't be their style to go out in the woods and stuff like that?

Devon: Probably not.

Thus, traditional discourses of gender were deployed in characterising girls and young women as town-based, less adventurous, delicate and safer than boys and young men. Some of the girls and women took up subject positions within such discursive constructions in an unquestioning way. For example, one female participant from Burnt Islands explained that hunting and fishing were "not the type of thing for girls" while another suggested that such activities were "gross and boring," both suggesting that they preferred town-based activities, closer to home. The citational performance of such discourses serves to produce and police the discursive boundary between normative rural femininity and masculinity, thus interpellating and regulating localised leisure performances of girls and boys, men and women. Such discursive utterances have been found to forcibly materialise particular gender (and aged, classed, sexed etc.) performances in other contexts (Davies, 2000; 2006) and thus it is hardly surprising that they are circulating in rural Newfoundland communities. What is interesting, however, is how these discursive constructions are emplaced in ways unique to rural Newfoundland. In other words, we argue, there are subtle but pervasive differences in how discourses of 
gender operate within the rural contexts under investigation. Although beyond the scope of the present argument, it is worth noting in passing that the binary between the feminine-town and masculine-woods was, as with all binaries, a decidedly messy one. In other words, there were differences between how the participants described their towns, with many of the smaller communities that had few retail outlets being characterised as masculine spaces when contrasted with larger towns with a more extensive consumer retail culture. Nonetheless, when contrasted with 'the woods', even smaller towns still assumed feminine attributions. Thus, the binary construction of the town/woods was shifting and fluid and contextually specific. The binary opposition between town/woods proved to be an organising dichotomy that was mapped onto other, more culturally dominant binaries, particularly the dichotomy between masculinity/femininity, and that such constructions forcibly materialised specific rural embodied subjectivities.

\section{Femininising 'the Town'}

In contrast to the cultural coding of the woods as masculine spaces of adventure, conquest and freedom, the participants understood their communities as feminine, and talked about them as though they were the rightful place of girls and women. Rural towns, particularly slightly larger rural towns with somewhat of a retail culture, were constructed as feminine spaces, where girls and women could shop and "hang out". Many of the participants noted the gendered consumer culture that characterised their towns, pointing to this as a primary difference in the recreational town-based opportunities available to men and women, a difference which lead them to the conclusion that rural towns were better suited to 'girls'. 
Moss: Why do you think it is that they [girls and boys] do different things?

Martin: Well, 'cause there's, I think that there's more things around here [town of Port aux Basques] for girls then there are for boys.

Moss: $\quad$ How so?

Martin: $\quad$ Because most of the stores are clothing stores for girls, like Ardene's is a girls’ clothing store with lots of girls’ accessories, but a lot of boys go there too, but it’s mainly a girls' store. Girls can go, like it’s mostly girls' stuff.

Moss: $\quad$ Such as, can you give another example?

Martin: Well, there's shopping, there's—-[pause] tryin' to think if there's anything else-hair salons, there's a lot of hair salons. Boys don't usually go there unless they need their hair cut, but most boys around town get their hair cut long, like I got mine. But yeah, that's one of the differences [...]

Indeed, such stories both drew upon and contributed to broader discursive constructions of the woods as masculine and the consumer-oriented spaces of the more or less 'urban' as feminine. Such binary constructions were, however, fluid and contextually contingent. For instance, from the narratives of the participants it is evident that despite the acknowledgement that boys and girls do similar recreational activities (i.e. "a lot of boys go there too"), the participants nonetheless remained invested in preserving binary gender differences between the leisure practices of boys and girls. Indeed, the participants drew upon the discursive construction of the town/woods binary as a means of marking a border between the girls and boys, a border that is not necessarily reflective of the lived 
recreational practices of boys and girls, but nonetheless operates in constituting binarised rural gender identities. As other scholars have pointed out, rural towns are predominately constructed, experienced and organised around masculine needs and priorities (Kenway and Kraack, 2009; Marshall, 2001) and we argue that it is only when contrasted with the woods that the town comes to represent the feminine. Nevertheless, within the rural contexts that we explored, the town occupied the normative and rightful place for girls and women to socialise, play and, as we examine below, wait for the boys to return from the woods.

Many of the girls and young women talked about engaging in leisure practices that were rooted closer to their homes, practices that were less dependent on outdoor activities, such as hunting, fishing and “quading”, for example. Thus, rural gender relations were largely constituted in and through territorial mobilities and therefore rural gender subjectivities were experienced along spatial trajectories. Many of the female participants described "hang[ing] out" around town while the boys are "off doing their own thing”.

Sandra: $\quad$ My friends, like guy friends, like for example, they're all really good friends with my dad-it's weird-like they go fishing and they go huntin', do all kinds of weird stuff like that [laughs]. They do their own thing like that and us girls we just, oh god, we just hang out. It's funny 'cause it's not even like there's anything to do around here, but we always just make it fun. I think 'cause we got each other. [23 years]

Moss: $\quad$ So the things that guys and girls do for recreation, that's different? 
Sandra: $\quad$ Completely different. We'll meet up, like on the weekends, if we wanna go out, we'll all meet up at a certain place [...] we'll go on quad with them every once and a while, but they do their own thing during the day.

Moss: $\quad$ Do you like living in Burnt Islands?

Tina: I don’t really [pause] there’s nothing to do. [15 years]

Elizabeth: I don't really know how to explain it because I find in Burnt Islands is like [we are], like on the upside of town, at the shop, while the boys is off like doing their own little thing [hunting and fishing], but then after everyone else gets back in the group again and hangs out. So it's like, sometimes it could be boring and sometimes not, depending on the weather and what is going on that night. [15 years]

Teenage women often used passive terms to describe their rural leisure experiences (i.e. "hang out”, "boring” and "sat down") while, at the same time, strongly implying that the most fun was to be had when the boys returned from the woods and "everybody gets back in the group”, usually at night or on the weekends. In this way, rural recreational experiences, like gender itself (Connell, 2005), were experienced and understood relationally. Indeed, the multiple inter-relations of rural play are significant and worthy of further interrogation in and of themselves, albeit beyond the scope of the current paper. Suffice it to say, however, that the inter-generational, homosocial bonding that occurs "while the boys [are] off doing their own little thing" back in the woods, is central to the reproduction of "sacrosanct" masculinities within rural contexts. Sacrosanct 
masculinities, according to Kenway and Hickey-Moody (2009) refer to those crossgenerational practices that shore up the boundaries of accepted localised ways of performing maleness. Such all-male, inter-generational outdoor experiences prove to be integral to the cultivation of particular ways of being male within rurality (see also Bye, 2009). This serves to produce and reproduce the boundary between hardened, free, adventurous and independent outdoor masculinities and the softer, town-based femininities against which they are constructed.

Some scholars have argued that venturing in to and the conquest of 'nature' or 'the woods' is akin to the phallic desire to penetratively control the feminine 'Mother Earth', and that through such performances masculinity is confirmed and re-confirmed (see Brandth, 1995; Little, 2002). Our research reveals the spatial mobilities and freedoms that motorised recreational vehicles play in such desires and performances within the rural Newfoundland context. This is not to say that girls and women did not use dirt bikes, ATVs and snowmobiles, but that dominant representations of their usage linked them to boys, men and the masculine. Thus, while young men and women, in many cases, engaged in similar recreational practices, broader discursive representations were taken up and deployed in articulating a town/woods binary, thus foregrounding the recreational experiences of boys and men in the woods, while simultaneously diminishing the wooded experiences of girls and women. In other words, gender discourses served to occlude some experiences (i.e. girls in the woods, men in the town) while rendering others readily available (i.e. girls shopping, boys in the woods). Such discursive constructions thus naturalize gendered rural recreational practices, thereby stabilizing the binary division between masculinity and femininity and the hierarchies of privilege and 
oppression that are founded upon them. Moreover, these discursive constructions have real material effects on the way in which rural youth understand and engage in recreation, rendering some practices acceptable and normal, while foreclosing others. In this way, dominant representations of rural recreation are performative in that they constitute, rather than benignly reflect, the gender subjects they interpellate, inciting some towards town-based leisure practices, while compelling others to woods based recreations. Such representations provide youth with a set of discursive resources to understand and articulate their experiences in gendered ways, processes that serve to materialise embodied gender subjects.

\section{Conclusion}

While scholars have noted the binary divide between urban and rural (Hogan and Purcell, 2008; Kenway and Kraack, 2009; Leyshon, 2008), there has been less exploration of how rural youth construct their communities in similar ways using the town/woods dichotomy. In this paper we have argued that the binary opposition between 'the town' and 'the woods' was significant to the performance of place-based gender subjectivities within the context of rural Newfoundland. Although the participants often had difficulty articulating the distinct leisure practices of boys and girls, they nonetheless remained invested in accentuating gender differences, and deployed the town/woods to do so, arguing that the woods was the domain of boys and men, while the town was more aligned to girls and women. Such articulations not only drew upon broader discursive constructions of gender, rurality and recreation, but served to entrench and materialise localised gendered spatial performances. Thus, discourses of gender were taken up and performed by the participants as a set of spatial practices that incited boys and men to 
explore and play in the woods, while more or less constraining similar practices in girls and women. In other words, while the young men were encouraged to explore and play in the "freedom" and independence the woods offered, young women did not experience similar spatial mobilities, but were constructed as bound to their rural towns where, the participants explained, adult surveillance and control was prevalent.

Thus, we have illustrated how broader discursive constructs of rurality and masculinity are taken up and emplaced within specific geographic contexts in the production of localised sets of social relations. As such we have taken our research participants to be active, albeit discursively enabled (Butler, 1995; Davies, 2006), creators of localised gender subjectivities. Nevertheless, we have only articulated one set of gender relations. There were other multiple and fluid ways of doing gender and being masculine within the rural Newfoundland context. Indeed, not all boys and young men had equal access to the motorised recreational vehicles that seemed to be essential to the "freedom" associated with the woods, nor were all boys equally interested in outdoor recreations. Similarly, not all girls and young women were bound within the parameters of the town. Despite these alternative gender performances, most of the participants, nevertheless, remained largely uncritically and passively accepting of the way in which gender relations were constructed and re-constructed in and through normative recreational practices. Indeed, the gender relations we have outlined appeared to be dominant or "sacrosanct” (Kenway and Hickey-Moody, 2009) within the rural communities where we conducted the research. In the context of this paper there were indeed sacrosanct femininities at play in rural locals as well, which, when practiced alongside normative masculinities, were constitutive of culturally intelligible gender 
relations and embodied gender hierarchies of more or less powerful ways of being within a specific context. There were alternative—resistive even—gender performances noticeable within the rural communities. For example, Ronda, a fifteen year old young women from Port aux Basques, talked about dirt biking as freedom: "I can go everywhere on my dirt bike [...] there's nobody telling you what to do [...] on [my] dirt bike I'm free”. She described herself as an "outdoor person," but also recognized that there were "not very many" young women who participated in this sort of outdoor activity and, those that did, faced gender stereotypes from some of their peers and adults. Indeed, these alternative gender performances warrants further study and analysis, but is beyond the scope of this paper.

Previous research has addressed and critiqued various constructions of 'the rural'. This research builds on that tradition by providing a nuanced and contextual understanding of the invariably complex and contradictory ways that young people in rural communities experience and embody their gender, space, and spatial identities. By illustrating how youth on the west coast of Newfoundland navigate woods/town binaries, how masculinity is enacted in such spaces, and the feminisation of the town, this theoretically informed qualitative study has provided a rich and more detailed understanding of the social lives and worlds of rural Newfoundland youth. More importantly, it has demonstrated the capacity for youth-as agentic subjects-to dialogue in sophisticated ways about the spatial processes which shape and constrain their lives. 


\section{Reference List}

Alston, M. \& Kent, J. (2009). Generation X-pendable: The social exclusion of rural and remote young people. Journal of Sociology, 45(1), 89-107.

Bell, D. (2000). Farm boys and wild men: Rurality, masculinity, and homosexuality. Rural Sociology, 65(4), 547-561.

Bonnett, A. (1996). The new primitives: Identity, landscape and cultural appropriation in the mythopoetic men's movement. Antipode, 28(3), 273-291.

Brandth, B. (1995). Rural masculinity in transition: Gender images in tractor advertisements. Journal of Rural Studies, 11(2), 123-133.

Bull, J. (2009). Watery masculinities: Fly-fishing and the angling male in the South West of England. Gender, Place and Culture, 16(4), 445-465.

Butler, J. (1990). Gender Trouble: Feminism and the Subversion of Identity. New York: Routledge.

Butler, J. (1993). Bodies that Matter: On the Discursive Limits of "Sex". New York: Routledege. 
Butler, J. (1995). Contingent foundations: Feminism and the question of “Postmodernism”. In S. Benhabib, J. Butler, D. Cornell, and N. Fraser (eds.), Feminist contentions: A philosophical exchange. New York: Routledge, 35-58.

Bye, L. M. (2006). Masculinity and rurality at play in stories about hunting. Norwegian Journal of Geography, 57(3), 145-153.

Bye, L. M. (2009). ‘How to be a rural man’: Young men’s performances and negotiations of rural masculinities. Journal of Rural Studies, 25, 278-288.

Campbell, H. \& Bell, M. M. (2000). The question of rural masculinities. Rural Sociology, 65(4), 532-546.

Community Accounts (n. d. a.). Channel-Port aux Basques Sub-community. Community Accounts. Newfoundland \& Labrador Statistics Agency, Government of Newfoundland and Labrador. Retrieved October 15, 2010 from http://www.stats.gov.nl.ca/

Connell, R. W. (2005). Masculinities. Los Angeles: University of California Press.

Corbett, M. (2007). All kinds of potential: Women and out migration in an Atlantic Canadian coastal community. Journal of Rural Studies, 23, 430-442. 
Cloke, P. (2005). Masculinity and rurality. In B. van Hoven and K. Horschelmann (eds.) Spaces of Masculinity. New York: Routledge, 45-62.

Davies, B. (2000). A Body of Writing 1990-1999. Walnut Creek, CA: Altamire Press.

Davies, B. (2006). Subjectification: The relevance of Butler's analysis for education. British Journal of Sociology of Education, 27(4), 425-438.

Deleuze, G. \& Guattari, F. (1987) A Thousand Plateaus: Capitalism and Schizophrenia. Minneapolis, MN: The University of Minnesota Press.

Dunkely, C. M. (2004). Risky geographies: Teens, gender, and rural landscape in North America. Gender, Place and Culture, 11(4), 559-579.

Dunkely, C. M. \& Panelli, R. (2007). ‘Preppy-jocks’, ‘rednecks', ‘stoners’ and ‘scum’: Power and youth social groups in rural Vermont. In R. Panelli, S. Punch \& E. Robson (eds.) Global Perspectives on Rural Childhood. New York: Routledge, 165-203.

Edley, N. (2001). Conversation analysis, discursive psychology and the study of ideology: A response to Susan Peer. Feminism \& Psychology, 11(1), 136-140. 
Epp, R. \& Whitson, D. (2001). Introduction: Writing off rural communities? In R. Epp \& D. Whitson (eds.) Writing Off the Rural West: Globalization, Governments, and the Transformation of Rural Communities. Edmonton, AB: The University of Alberta Press, xiii-xxxv.

Foucault, M. (1972). The Archaeology of Knowledge. New York: Routledge.

Hogan, M. \& Pursell, T. (2008). The 'Real Alaskan’: Nostalgia and rural masculinity in the “Last Frontier”. Men and Masculinities, 11(63), 63-85.

Jackson, L. A., Tirone, S., Donovan, C. \& Hood, R. (2007). Community restructuring and the emotional and social health of youth: A study of a small coastal community in Newfoundland, Canada. Canadian Journal of Community Mental Health, 26(2), 71-89.

Jarosz, L. and Lawson, V. (2002). 'Sophisticated people versus rednecks’: Economic restructuring and class difference in America’s West. Antipode, 8-27.

Jones, O. (1999). Tomboy tales: The rural, nature and the gender of childhood. Gender, Place \& Culture, 6(2), 117-136.

Jones, O. (2000). Melting geography: Purity, disorder, childhood and space. In S. 
Holloway and G. Valentine (eds.) Children’s Geographies: Playing, Living, Learning. New York: Routledge, 29-47.

Jones, O. (2007). Rurality, power and the Otherness of childhood in British contexts. In R. Panelli, S. Punch and E. Robson (eds.) Global Perspectives on Rural Childhood and Youth: Young Rural Lives. New York: Routledge, 193-204.

Kraack, A. \& Kenway, J. (2002). Place, time and stigmatised youthful identities: Bad boys in paradise. Journal of Rural Studies, 18, 145-155.

Kenway, J., Kraack, A. \& Hickey-Moody, A. (2006). Masculintiy beyond the metropolis. New York: Palgrave McMiillan.

Kenway, J. \& Hickey-Moody, A. (2009). Spatialised leisure-pleasures, global flows and masculine distinctions. Social \& Cultural Geography, 10(8), 837-852.

Kvale, S. (1996). InterViews: An introduction to qualitative research interviewing. London: Sage Publications.

Leyshon, M. (2008). The betweeness of being a rural youth: Inclusive and exclusive lifestyles. Social \& Cultural Geography, 9(1), 1-26.

Liepins, R. (2000). Making men: the construction and representation of agriculture-based 
masculinities in Australia and New Zealand. Rural Sociology, 65(4), 605-620.

Little, J. (2002). Rural geography: Rural gender identity and the performance of masculinity and femininity in the countryside. Progress in Human Geography, 26(5), 665-670.

Little, J. \& Leyshon, M. (2003). Embodied rural geographies: Developing research agendas. Progress in Human Geography, 27(3), 257-272.

MacNaughton, P. \& Urry, J. (2000). Bodies in the woods. Body \& Society, 6(3-4), 166182.

Markula, P. and Pringle, R. (2006). Foucault, Sport and Exercise: Power, Knowledge and Transforming the Self. New York: Routledge.

Marshall, J. (2001). Connectivity and restructuring: Identity and gender relations in a fishing community. Gender, Place and Culture, 8(4), 391-409.

Massey, D. (1998). The spatial construction of youth cultures. In. T. Skelton and G. Valentine (eds) Cool Places: Geographies of Youth Cultures. New York, Routledge, 121-29.

Matthews, H., Limb, M. \& Taylor, M. (1999). Reclaiming the street: the discourse of 
curfew. Environment and Planning A, 31(10), 1713-1730.

Matthews, H., Taylor, M., Sherwood, K., Tucker, F. and Limb, M. (2000). Growing-up in the countryside: Children and the rural idyll. Journal of Rural Studies, 16, 141153.

McGrath, B. (2001). ‘A problem of resources’: defining rura youth encounters in education, work \& housing. Journal of Rural Studies, 17, 481-495.

Mowat, F. (2006). Bay of Spirits: A Love Story. Toronto, ON: McClelland \& Stewart.

Narin, K. \& Panelli, R. (2009). Using fiction to make meaning in research with young people in rural New Zealand. Qualitative Inquiry, 15(1), 96-112.

Ni Laoire, C. (2007). The ‘green grass of home’? Return migration to rural Ireland. Journal of Rural Studies, 23, 332-344.

Norman, M., Power, N. \& Dupre, K. (2010). Playing Where You Work: Rural Newfoundland Youth and Intersections of Work, Play \& Health. Paper presented at the Canadian Association for Research on Work and Health. Toronto: ON.

Ormer, R. (2007). Coasts Under Stress: Restructuring and Socio-Ecological Health. Montreal, QC: McGill-Queens University Press. 
Panelli, R. (2002). Young rural lives: Strategies beyond diversity. Journal of Rural Studies, 18, 113-122.

Panelli, R., Narin, K. \& McCormack (2002). 'We make our own fun’: Reading the politics of youth with(in) community. Sociologia Ruralis, 42(2), 106-130.

Peter, G. \& Bell, M. (2004). Farming. In M. Kimmel \& A. Arnson (eds.) Men and masculinities: A social, cultural and historical encyclopedia. Santa Barbra, CA: ABC-CLIO, 272-74.

Philo, C. (1992). Neglected rural geographies: a review. Journal of Rural Studies, 8, 193207.

Power, N. (2005). What Do They Call a Fisherman? Men, Gender, and Restructuring in the Newfoundland Fishery. St. John's, NL: Institute of Economic and Social Research.

Pringle, R. \& Markula, P. (2005). No pain after all: A Foucaultian analysis of masculinities and men's experiences in rugby. Sociology of Sport Journal, 22, $472-497$.

Rye, J. F. (2006). Rural youths' images of the rural. Journal of Rural Studies, 22, 409- 
Sibley, D. (1995). Geographies of Exclusion. New York: Routledge.

Shoveller, J., Johnson, J., Prkachin, K. \& Patrick, D. (2007). ‘Around here, they roll up the sidewalks at night': A qualitative study of youth living in a rural Canadian community. Health \& Place, 13, 826-838.

Smith, L. T., Smith, G., Boler, M., Kempton, M., Ormond, A., Chueh, H. \& Waetford, R. (2002). 'Do you guys hate Aucklanders too?’: Youth voicing difference from the rural heartland. Journal of Rural Studies, 18, 169-178.

Tucker, F. \& Matthews, H. (2001). ‘They don’t like girls hanging around here’: Conflicts over recreational space in rural Northamptonshire. Area, 22(2), 161-168.

Valentine, G. (1997). A safe place to grow up? Parenting, perceptions of children’s safety and the rural idyll. Journal of Rural Studies, 13(2), 137-148.

Valentine, G., Skelton, T. \& Chambers, D. (1998). Cool places: An introduction to youth and youth cultures. In. T. Skelton and G. Valentine (eds) Cool Places: Geographies of Youth Cultures. New York, Routledge, 1-34. 
Valentine, G., Holloway, S. Knell, C. \& Jayne, M. (2008). Drinking places: Young people and cultures of alcohol consumption in rural environments. Journal of Rural Studies, 24, 28-40.

Vanderbeck, R. \& Dunkley, C. M. (2003). Young people’s narratives of rural-urban difference. Children’s Geographies, 1(2), 241-259.

Van Herk, G., Childs, B. \& Thorburn, J. (2007). Identity marking and affiliation in an urbanizing Newfoundland community. PAMAPLA/ACAAPLA, 31, 85-94.

Ward, C. (1990). The Child in the Country. London: Belford Square Press.

Weedon, C. (1997). Feminist Practice and Poststructuralist Theory. Cambridge, MA: Blackwell Publishers.

Wetherell, M. (1998). Positioning and interpretative repertoires: Conversation analysis and post-strucuturalism in dialogue. Discourse \& Society, 9(3), 387-412.

Wetherell, M. (2003). Racism and the analysis of cultural resources in interviews. In H. Van den Berg, M. Wetherell \& H. Houtkoop-Steenstra (eds.) Analysing race talk: Multidisciplinary approaches to the interview. Cambridge: Cambridge University Press, 11-30. 
Wright, J. (2004). Post-structural methodologies: The body, schooling and health. In J.

Evans, B. Davies and J. Wright (eds.) Body Knowledge and control: studies in the sociology of physical education and health. New York: Routledge, 19-32.

\footnotetext{
${ }^{i}$ Port aux Basques is on the southwest coast of the island of Newfoundland and is one of the communities where the present research was conducted.

${ }^{\text {ii }}$ Farley Mowat is a famous, albeit contentious, author and animal rights activist who has written extensively about Canada's hinterlands, including several stories and a memoir set on the island of Newfoundland.

iii Drs Nicole Power (Memorial University), Moss Norman (Concordia University), Kathryne Dupré (Memorial University), and Arla Day (St. Mary's University) are the investigators on this project. The authors of this paper acknowledge Dr. Day's early contribution to the development of the focus group tool. iv The Community-University Research for Recovery Alliance (CURRA) initiative is funded by the Social Sciences and Humanities Research Council of Canada (SSHRC) through its Community-University Research Alliance (CURA) program (grant number 833-2007-1027) and by Memorial University of Newfoundland, with additional financial and in-kind support from numerous community partners and groups (www.curra.ca). The Rural Youth subcomponent is also supported by the Canadian Institutes of Health Research [GTA92108].

${ }^{\mathrm{v}}$ Woody Point and Trout River are located in Gros Morne, a United Nations Educational, Scientific and Cultural Organiation (UNESCO) world heritage site.

vi Vanessa Farrell, coordinator for the southwestern branch of the CYN, was instrumental as a community contact in helping to recruit participants. This research would not have been possible without her local knowledge and dedication to the project.

vii Researchers on this project included Drs Nicole Power, Kate Dupre (Memorial University of Newfoundland), Arla Day (St. Mary's University). This research was funded by a Canadian Institute for Health Research, Centre for Research Development grant to the Atlantic Rural Centre for Dalhousie University.
} 
viii "Hoody" is a term used to describe a hooded sweatshirt.

ix The participants used various terms to refer to their off-road recreational vehicles, such as ATV (All Terrain Vehicles), quads and "four wheelers". All of these terms refer to small, four wheeled, one (sometimes two) person, machines that are designed to be driven on trails and rough terrain.

${ }^{\mathrm{x}}$ Issues of safety in relation to the woods came up with some of the younger participants, where they described having to be accompanied by older siblings or parents. With older youth, however, issues of safety were discussed more in terms of adult-youth conflicts, with several of the youth, for example, talking about "cranky" adults telling them to slow down on their ATVs. Other than these discussions of safety, the youth seemed to understand the woods as a safe place to play.

${ }^{x i}$ We made the decision to represent the local dialects of the youth to the best of our ability. For instance, while the non-pluralised "live" would be the grammatically correct usage in this sentence, it is common for Newfoundlanders to pluralise the singular (e.g. "I knows it" or "I lives for it"), what Van Herk, Childs \& Thorburn (2007) refer to as "non-verbal s-marking”. Indeed, "linguistic choices figure prominently in [Newfoundlanders] representations of self and place" (p. 85) and, as such, we resisted the temptation to 'correct' their language use. This is a political as well as methodological decision. 